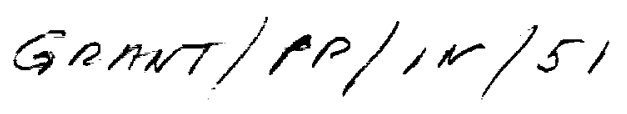

\title{
PLANT GROWTH DURING THE GREENHOUSE II EXPERIMENT ON THE MIR ORBITAL STATION
}

\author{
F.B. Salisbury', W.F. Campbell', J.G. Carman ', G.E. Bingham ${ }^{2}$, D.L. Bubenheim, ${ }^{3}$ B. Yendler ${ }^{3}$, V. Sytchev ${ }^{4}$, \\ M.A. Levinskikh ${ }^{4}$, I. Ivanova ${ }^{4}$, L. Chernova ${ }^{4}$, and I. Podolsky ${ }^{4}$ \\ ${ }^{\prime}$ Department of Plants, Soils, \& Biometeorology, Utah State University, Logan, UT 84322-4820, USA. \\ ${ }^{2}$ Space Dynamics Laboratory, Utah State University, 1695 N. Research Park Way, North Logan, UT 84341, USA. \\ ${ }^{3}$ NASA Ames Research Center, Moffett Field, CA 94035, USA. \\ ${ }^{+}$Institute of Biomedical Problems, 123007 Khoroshevskoe sh, 76a, Moscow, Russia.
}

\begin{abstract}
We carried out three experiments with Super Dwarf wheat in the Bulgarian/Russian growth chamber Svet $\left(0.1 \mathrm{~m}^{2}\right.$ growing area) on the Space Station Mir. This paper mostly describes the first of these NASA-supported trials, began on Aug. 13, 1995. Plants were sampled five times and harvested on Nov. 9 after 90 days. Equipment failures led to low irradiance ( 3 , then 4 of 6 lamp sets failed), instances of high temperatures (ca. $37^{\circ} \mathrm{C}$ ), and sometimes excessive substrate moisture. Although plants grew for the $90 \mathrm{~d}$, no wheat heads were produced. Considering the low light levels, plants were surprisingly green, but of course biomass production was low. Plants were highly disoriented (low light, mirror walls?). Fixed and dried samples and the root module were returned on the U.S. Shuttle Atlantis on Nov. 20, 1995. Samples of the substrate, a nutrient-charged zeolite called Balkanine, were taken from the root module, carefully examined for roots, weighed, dried, and reweighed. The Svet control unit and the light bank were shipped to Moscow. An experiment validation test (EVT) of plant growth and experiment procedures, carried out in Moscow, was highly successful. Equipment built in Utah to measure $\mathrm{CO}_{2}, \mathrm{H}_{2} \mathrm{O}$ vapor, irradiance, air and leaf (IR) temperature, $\mathrm{O}_{2}$, pressure, and substrate moisture worked well in the EVT and in space. After this manuscript was first prepared, plants were grown in Mir with a new light bank and controller for 123 d in late 1996 and 39 days in 1996/1997. Plants grew exceptionally well with higher biomass production than in any previous space experiment, but the ca. 280 wheat heads that were produced in 1996 contained no seeds. Ethylene in the cabin atmosphere was responsible.
\end{abstract}

\section{INTRODUCTION}

It is important to study the basic biology of plant responses to gravity, which can be done in the microgravity environment of a space craft. It has also long been a goal to achieve maximum yields of edible plant products for future use in a bioregenerative life-support system (BLSS). Special problems will be encountered if a BLSS is to be operated in a microgravity environment (much easier on the moon or Mars). These considerations form the background for plant experiments in space. Short-duration plant experiments in space (e.g., on the U.S. Space Shuttle) have resulted in abnormal plant responses, but sometimes plant growth was quite comparable to ground controls (e.g., Dutcher et al., 1994; Nechitailo \& Mashinsky, 1993). This is especially true for plants grown in an agar medium (ample aeration and nutrient supply), especially if plants were seedlings still obtaining nutrients from seed stores (Lewis, 1995). The paramount achievement of long-duration plant experiments in space was the growth of Aribidopsis thaliana through a complete life cycle (Merkies et al., 1982) by Soviet scientists in the Phyton III device in Salyut Seven. There were no "show stoppers," but plant growth was retarded and generally rather poor. Seeds formed in space germinated but at a low percentage compared with ground controls. Soviet scientists also grew wheat plants in space including the Super-Dwarf cultivar used in our experiments. Again, although heads eventually formed after about 140 days (and 
developed after return to earth), growth was generally rather poor (Mashinsky et al, 1994).

The primary question is whether the poor growth of plants in long-duration space experiments was caused by microgravity or by some other limiting environmental parameter. Certainly there were many such parameters that could have been limiting: Photon fluxes were low, carbon dioxide levels were high and fluctuating, temperature fluctuated (usually around a temperature suitable for plant growth but sometimes increasing to $37^{\circ} \mathrm{C}$ ), and root conditions may well have included too much or too little water and possibly even unavailable nutrients. With so many factors potentially limiting plant growth, it was premature to suggest that microgravity alone might limit the use of plants in a future BLSS. Such considerations were the foundation for our experiment.

\section{THE SHUTTLE/MIR EXPERIMENTS WITH SUPER-DWARF WHEAT}

On August 12, 1995, Super-Dwarf wheat seeds were planted in the Bulgarian/Russian growth chamber Svet in the orbital station Mir. Plants were sampled five times, some photographs were taken, and fixed and dried samples including a final harvest and some items of equipment were returned to earth on November 20, 1995 (90 days in space; this paper was originally prepared to describe this 1995 experiment). On August 5, 1996, seeds were again planted in Svet on Mir. They were sampled four times plus the final harvest on December 6, 1996 (123 days), at which time a second crop was planted to produce plants that were harvested on January 14, 1997 (39 days). These green plants were frozen in the $\mathrm{GN}_{2}$ freezer and returned to earth along with the other samples and equipment on January $22,1997$.

The goals of our Mir experiments were as follows:

1. Grow Super-Dwarf wheat through a complete life cycle in Svet (in the Krystal Module of Mir).

2. Document environmental parameters:

- $\mathrm{CO}_{2}$ concentration, allowing calculations of photosynthesis and respiration.

- Water vapor allowing calculation of transpiration.

- Leaf (infrared), air, and substrate temperatures.

- Total cabin pressure and oxygen levels.

- Substrate moisture conditions (16 probes).

3. Collect samples and photographs for analysis.

It should be noted that we used Super-Dwarf wheat not because it has agronomic values that might qualify it for future use in a BLSS, but simply because it was short enough to be grown in Svet. Actually, it has low yields and a relatively low harvest index (percentage of grain mass to total plant mass).

\section{NOTES ON SVET}

Svet was designed by Russian scientists at the Institute of Biomedical Problems in Moscow in collaboration with Bulgarian scientists at the Bulgarian Academy of Sciences Space Research Institute, where Svet was constructed under the direction of Tania Ivanova and others. Svet has $0.1 \mathrm{~m}^{2}$ of growing area. A controller is programmed to control length of the photoperiod and addition of water to the substrate when a sensor indicates that the substrate is drying out. As noted below, we encountered problems with this controller, and it was replaced with a more sophisticated version for the 1996 experiment. Photosynthetic photon flux in Svet, thanks to mirror-Mylar walls applied in space to the inside of Svet for the 1995 experiment, reached about $100-150 \mu \mathrm{mol} \cdot \mathrm{m}^{-2} \cdot \mathrm{s}^{-1}$. The light bank for the 1995 experiment consisted of twelve 8-W fluorescent tubes arranged into 6 sets of two tubes each. For the 1996 experiment, a new light bank was developed using 6 modern Osram Delux S 11-W/21, 900 lumen, LUMILUX Hellweiss (cool white) U-tube fluorescent lamps with highly efficient power supplies (modified by the Bulgarian engineers), reducing the heat generated by the unit by two thirds while maintaining ca. $350-400 \mu \mathrm{mol} \cdot \mathrm{m}^{-2} \cdot \mathrm{s}^{-1}$ at the plant level. These lamps were cooled by air drawn over them with a fan. This air movement maintained temperature of the plants in Svet just slightly above the cabin air temperature.

Because there is no water drainage in microgravity, the substrate posed a particularly challenging problem. The Svet root module consists of two compartments, each one supporting two rows of plants (26 seeds planted in each row in our experiments). The substrate is a nutrient-charged zeolite developed in Bulgaria and called Balkanine. It's particle size varies, and the size must be a compromise between effective capillary transfer of water (small particle size) and adequate root aeration (larger particles). In 1995, we used rather tightly packed Balkanine with particle sizes of two parts 1-2 mm and one part 2-3 mm. For 1996, we used only 1-2 mm Balkanine. Water is added through a socalled hydro accumulator to a wicking material folded around the hydro accumulator. This material extends upward, with lateral pieces near the surface that extend to the moisture sensor a few centimeters below the surface. Seeds are planted between the two layers of the wicking material near the surface. The plant roots penetrate the wick material and extend into the Balkanine where the nutrients are located. 
Under the direction of Gail Bingham at the Space Dynamics Laboratory, Utah State University, a complex set of instrumentation was developed for use in our Mir/Shuttle experiments. The biggest challenge was to develop infrared (IR) $\mathrm{CO}_{2}$ analyzers that could measure carbon dioxide concentration entering and leaving two plastic cuvettes. This required four analyzers that measured $\mathrm{CO}_{2}$ up to a concentration of $2 \%$ with an accuracy of $\pm 0.035 \%$. Other sensors, some installed in the plastic cuvettes and others in the airstream, included infrared temperature sensors aimed at the canopy area, conventional air-temperature sensors, photon-flux sensors, humidity sensors (IR), and pressure and oxygen sensors. Humidity was measured by the same infrared sensors that measured $\mathrm{CO}_{2}$. Pressure and oxygen, as well as cabin temperature, were measured in the Environmental Data System before air entered the cuvettes. All the data from these sensors were stored on hard disks of an IBM 750C notebook computer, which also controlled the entire system. Svet and the attached Utah instrumentation were installed in the Krystal Module of Mir close to the entrance hatch to which the Shuttle was docked; indeed, the open hatch door cleared our equipment by only about $1 \mathrm{~cm}$.

A leaf area meter was sent to Mir so that the cosmonauts could measure leaf areas of sampled plants, but this was never done. Instead we measured leaf areas of fixed samples after they were returned to earth. The leaf-temperature and air-temperature sensors, along with the photon-flux sensor, were to be located in each of the two plastic cuvettes.

\section{EXPERIMENTAL PROCEDURES IN FLIGHT}

In addition to many small activities that were carried out to keep our experiment functioning, four primary experimental procedures that the cosmonauts/astronauts were to carry out are listed in Table 1.

\section{Table 1. Four primary experimental procedures for the experiments with Super-Dwarf wheat in Svet on Mir}

1. Record environmental data (mostly automatically in notebook computer but also manually in a log book).

2. Take regular photographs from a camera bracket that allowed stereo views of the plants from two levels, with a color-chart/ruler included in the photos. (The camera bracket was misplaced in Mir and never used! Videos were taken, however, including the color-chart/ruler, and transmitted to earth.)

3. Take regular samples, some chemically fixed in special bags, with excess material as well as material taken from the final harvest being stored and dried in bags that contain desiccant.

4. Carry out a final harvest, mostly dry material. (The second planting in 1996/1997 produced 39-day-old plants that were frozen in the $\mathrm{GN}_{2}$ freezer.)

\section{THE 1995 EXPERIMENT}

Svet was installed on Mir in 1990, and the Utah equipment was delivered to Mir in the Spektr module on June 1, 1995. (Spektr became a permanent part of Mir.) STS-71 delivered a root module and seeds to Mir on July 4, 1995. (Two root modules were already on Mir, but the new one was an improved design.) The samples, root module, hard disks, controller, and light bank were returned to earth on STS-74, November 20, 1995. Some key events in the 1995 experiment are shown in Table 2; actual sampling dates for the 1995 experiment are shown in Table 3.

Many of the members of our team were present to receive the samples and other equipment. There were 4 of us from Utah, 4 from Moscow, 6 from NASA Ames, and photographers from the Kennedy Space Center as well as Jay Garland from the Kennedy Space Center who helped collect and then analyze samples for microorganisms. About 130 samples of Balkanine were taken from the two compartments of the root module, carefully examined for roots, weighed, dried, and reweighed. Most of the roots were in the wick material although a few, very fine roots were found in virtually all the Balkanine samples. One compartment of the root module was much wetter than the other compartment; indeed, near the center the Balkanine in one cuvette was saturated while the other was nearly dry. This was visually obvious. (Measured data are unreliable because of drying during sampling.) Fixed samples were carefully transferred to fresh fixative, and both fixed and dried samples were shipped to the NASA Ames Research Center and to Russian and U.S. investigators. Returned equipment included the Svet control unit and the light bank, which were shipped to Moscow and then to Bulgaria, where the engineers examined the units to understand the failures noted below. Hard discs were also returned on STS-74, and data from these were extensively analyzed.

Unfortunately, there were several unplanned occurrences during the 1995 experiment that had strongly negative, almost fatal effects on the outcome of the experiment. To begin with, the MIPS (Mir Interface to Payload System) failed so that we had no telemetry downlink of our data in near real time. Such a down link would have prevented some of the problems, especially with the moisture levels in the substrate. Cosmonauts read the data from the screen of our notebook computer to the ground contact (usually Margarita Levinskikh). This worked fairly well, but it meant 
Table 2. Some Events in the 1995 Experiment

\begin{tabular}{|c|c|}
\hline Event & Date \\
\hline $\begin{array}{l}\text { Equipment set up } \\
\text { MIPS (Mir Interface to Payload Systems) failed; } \\
\text { no data downlink. } \\
\text { Water added to root module (two compartments). } \\
\text { Margarita Levinskikh voice contact with Nickoli Budarin. }\end{array}$ & July $24-25$ to August 11 \\
\hline Seeds planted & August 12,$1995 ; 22: 30$ \\
\hline Lights turned on & August 14 \\
\hline $\begin{array}{l}\text { Three lamp sets failed to come on } \\
\text { Leaf bags (cuvettes) removed } \\
\text { Problems in maintaining proper moisture level }\end{array}$ & August 15 \\
\hline $\begin{array}{l}\text { Control unit failed } \\
\text { Lights turned on \& off manually from then on } \\
\text { Photoperiods varied around } 12-14 \mathrm{~h} \\
\text { Watering (water injection) carried out manually }\end{array}$ & August 16 \\
\hline $\begin{array}{l}\text { Number of plants about } 57 \text { (104 seeds planted) } \\
\begin{aligned} \text { cuvette } \# 1=\text { about } 40 \\
\text { cuvette } \# 2=17\end{aligned}\end{array}$ & August 24 \\
\hline $\begin{array}{l}\text { Control unit completly died (i.e., no light) } \\
\text { Frantic calls between Moscow, Bulgaria, \& SDL } \\
\text { Bingham gave instruction to "hot wire" with paper clips. } \\
\text { It worked. Back in business! }\end{array}$ & September $5-7$ \\
\hline $\begin{array}{l}\text { Ground wire not hooked to lights } \\
\text { Data difficult to interpret }\end{array}$ & $\begin{array}{l}\text { August } 15 \text { to } \\
\text { September } 15\end{array}$ \\
\hline $\begin{array}{l}\text { Fan failed while lights were on } \\
\text { No convection: heat built up around lamps } \\
\text { Plant temperature may have reached } 35-37^{\circ} \mathrm{C} \\
\text { Video shows only two lamp sets functional } \\
\text { About } 90-110 \mu \mathrm{mol} \cdot \mathrm{m}^{-2} \cdot \mathrm{s}^{-1} \text {, less at plant level. }\end{array}$ & September 18 \\
\hline $\begin{array}{l}\text { Out of Mir water (Ag)--used Shuttle water } \\
\text { lodine used to purify: maybe } 4 \mathrm{mg} / \mathrm{L}\end{array}$ & September 28 \\
\hline \multicolumn{2}{|l|}{$\begin{array}{l}\text { Four videos taken at various times } \\
\text { Camera bracket lost in Mir! }\end{array}$} \\
\hline Samples and equipment returned on STS-74 to KSC & November 20 \\
\hline
\end{tabular}

Table 3. Dates of Plant Sampling and Fixation in the 1995 Experiment

August 26: 14 days after planting seeds

August 31: 19 days

September 16: 35 days

October 04: 53 days

October 25: 74 days

November 09: 90 days (final harvest) 
that 2-3 days might elapse from the time a reading was made until suggestions could be relayed back to Mir relating to watering and other procedures.

The lights were tested on August 14, wo days after planting the seeds, and they worked well; on August 15, however, three of the six lamp sets failed to come on and were permanently disabled throughout the experiment. By September 18 when a video was made and down linked, it was apparent that only 2 of the 6 sets were functioning. In any case, the cosmonauts deduced that the lamps had failed because they got too hot, perhaps because of restricted air flow around the leaf bags (cuvettes). Hence, the leaf bags were removed, meaning that no photosynthesis, respiration, or transpiration measurements could be made. $\mathrm{CO}_{2}$ and water vapor were measured in the cabin air, however, which constituted a continuing test of the Utah equipment; the equipment functioned well. Study of the light bank in Bulgaria found that the problem was most probably related to a fan failure, which melted the insulators in the power transistors in the light bank.

On August 16 the control unit failed, which meant that the lights had to be turned on and off manually. Cosmonauts were not consistent in doing this, so photoperiods varied around 12-14 h, with some being considerably shorter and others a bit longer-including continuous light for 2 or $3 \mathrm{~d}$ near the end of the experiment and continuous darkness for a few days near the beginning of the experiment. By August 24, there were about 57 plants growing of the 104 seeds that were originally planted. Poor germination may have resulted from over watering during the first 2 or 3 days. It took us a few days to realize that when the watering system was turned on more water was going to one cuvette than to the other. There was no way to correct this. For the 1996 experiment, flow meters were installed, making it possible to control and monitor the amount of water supplied to each cuvette.

On September 5-7, the control unit completely failed so that lights could not be turned on or off. After some consultation, Bingham gave instructions to "hot wire" with paper clips from the Utah power source to the controller to increase the voltage to the required $12 \mathrm{~V}$. This worked, and after $3 \mathrm{~d}$ the lights were back on and functioning.

From August 15 to September 15, a ground wire had not been attached properly to the lights. This resulted in false readings of the data. (It appeared, for example, that light levels were reaching $600 \mu \mathrm{mol} \cdot \mathrm{m}^{-2} \cdot \mathrm{s}^{-1}$ even though 3 or 4 of the lamp sets had failed!) Actual light levels were probably as low as $60-80 \mu \mathrm{mol} \cdot \mathrm{m}^{-2} \cdot \mathrm{s}^{-1}$, close to the compensation light level for wheat.

On September 18, the fan that cools the lights failed again, leading to increased temperatures. The infrared thermometer suggested that the plants might have reached $35-37^{\circ} \mathrm{C}$.

Water supplied to the Balkanine was originally kept free of microorganisms by addition of silver fluoride. The silver would probably be precipitated as chloride and unavailable to plants. After September 28, Shuttle water was used, and this contained iodine (about $4 \mathrm{mg} \cdot \mathrm{L}^{-1}$ ). Ground tests showed that this was probably not deleterious; nevertheless, $8 \mathrm{mg} \cdot \mathrm{L}^{-1}$ clearly inhibited plant growth in these tests.

The specially designed camera bracket that would have allowed stereo photography was misplaced on Mir! Hence, no stereo photos were taken in either experiment. Some photos were taken with Kodak Gold 400, but we saw only the videos, which were transmitted to earth at intervals.

\section{GROUND-BASED STUDIES}

We carried out many ground-based studies in Utah, NASA Ames Research Center, and Moscow. For example, from February 21 to May 24, 1995, plants were grown in Moscow through a complete life cycle in a ground-based version of Svet with the Utah instrumentation attached. This was called the Experiment Validation Test (EVT). Plants were demonstratively healthy, producing normal, viable seeds and thus demonstrating that the light levels and other environmental parameters potentially available in Svet (even with the original 1995 lamps) were sufficient to carry plants from seed to seed. The Utah instrumentation functioned well although there was too much variation in ambient $\mathrm{CO}_{2}$ concentrations to allow photosynthesis and respiration measurements as originally planned. Another approach was used to obtain some valid data on photosynthesis (disabling automatic control of the fans to stabilize their flow rate and hence the $\mathrm{CO}_{2}$ concentration). The experiment was repeated in Moscow from October 24, 1995 to January 22, 1996 in a so-called Chamber Test in which three crew members were sealed in a chamber for about three months as part of an experiment in the psychology of confinement. The new Bulgarian light bank was tested (although it subsequently had to be modified to be flight qualified, reducing the light somewhat). Again plants were healthy, producing more biomass than in the EVT as expected because of the higher light levels, but for unknown reasons seed yields were somewhat reduced compared with the EVT. Some photosynthesis data were obtained in the Chamber Test.

In many studies too numerous to describe here, both in Utah and at NASA Ames, we examined effects of high $\mathrm{CO}_{2}$ levels (in a battery of 12 foam-board Svet mockups), low photon fluxes and various photoperiods, various substrates including hydroponics, micro techniques used in examination of returned samples (light and electron micro- 
scopes; see Campbell et al., 1996), chemical analysis techniques, use of the $\mathrm{GN}_{2}$ for returned samples, water relations of Balkanine, functions of the moisture sensors, many tests of the Utah instrumentation, and tests of in-flight procedures.

A synchronous control experiment was set up at NASA Ames to duplicate, as far as possible, the changing environment experienced by the plants in the 1995 experiment. At the low light levels, plants grew as poorly as they did on Mir, but heads always formed, these containing a few seeds.

\section{SOME CONCLUSIONS OF THE 1995 EXPERIMENT}

We were gratified that the Utah instrumentation functioned well. Nevertheless, in spite of the 16 moisture sensors and largely because of the failure of the MIPS system and the Svet controller, it was very difficult to maintain a suitable moisture level in the Balkanine. There was a steep moisture gradient from the wick to the edge of the module, for example, indicating the slow capillary transfer of water in Balkanine that had relatively large particle sizes-also clear from our ground studies. The smaller sizes used in this experiment compared with the 1990 experiment (Ivanova $e t$ $a l ., 1992)$ were apparently an improvement. In any case, the Utah moisture probes were extremely helpful, and much was learned about water management.

The plants stayed alive for almost the entire $90 \mathrm{~d}$. The videos and photographs showed plants with an apparently healthy green color although they were disoriented (like "crabgrass"). We assumed that microgravity combined with the mirror walls so that light was not unidirectional was the cause of this disorientation. Nevertheless, we have observed similar disorientation when plants are grown under low light levels on earth, even without the mirror walls. Fixed samples confirmed the healthy green color of the young plants although photos taken at about the time of the 74-day sampling show that many plants were yellow and apparently dead. The cosmonaut must have sampled only healthy plants at that time. As expected under such a low photon flux and with the problems in maintaining ideal moisture levels in the substrate, the biomass production was very low. Because most of the roots remained in the wick material, plants may have been somewhat nutrient stressed.

Perhaps the most interesting biological observation was that the plants remained almost completely vegetative. There were no signs of heads in any of the returned samples including the final harvested plants. Microscopic - examination revealed a few very young floral primordia on a very few plants. Some plants made as many as 18 leaves with no flowers instead of the usual 8 leaves, after which plants normally form a head.

Why did the plants remain vegetative? We tested low light and found that, by itself, it did not result in vegetative plants. Even when photon fluxes were so low $\left(40 \mu \mathrm{mol} \cdot \mathrm{m}^{-2} \cdot \mathrm{s}^{-1}\right)$ that plants actually died before reaching maturity, floral primordia and sometimes sterile heads were apparent; plants at $80 \mu \mathrm{mol} \cdot \mathrm{m}^{-2} \cdot \mathrm{s}^{-1}$ typically formed sterile heads. We thought that perhaps the heat shock $\left(37^{\circ} \mathrm{C}\right.$ on September 18) might have produced vegetative plants, but duplicating this treatment both under greenhouse conditions and with low light failed to keep plants vegetative in our ground tests. (We tested $40^{\circ} \mathrm{C}$ given for $1-24 \mathrm{~h}$ to different sets of plants at up to 30 days old.) What was the role of microgravity in maintaining vegetative plants? Because wheat heads had formed previously in microgravity (Mashinsky et al., 1994), we could not ascribe their vegetative condition completely to microgravity. A combination of factors seemed more likely, and one of these combined factors might well have been microgravity-or ethylene (see below).

\section{RESULTS OF THE 1996/1997 EXPERIMENTS}

Plant growth during the $1996 / 1997$ experiments was much better than it was in 1995, as was to be expected with the higher irradiance levels (Salisbury, 1997; Levinskikh et al., 2000). Plants were sampled into chemical fixative (excess material into desiccant bags) at 21,39,52, and 63 days, with a final harvest on 06 Dec 1996 (123 growing days). The plants produced far more biomass than had been obtained in any previous space experiment: about $1 \mathrm{~kg}$ of dry material (even after removal of considerable biomass as samples). About 64 of the 104 seeds germinated, and about half of these plants were removed for sampling. We saw 14 videos during the 1996 experiment. Most leaves appeared healthy and green. Heads began to form during late September and early October, with a total of about 280 eventually forming. The developing heads appeared almost normal in the videos. Nevertheless, when the mature, dried heads were returned to earth, there was not a single seed in any of them. Microscopic analysis of a sizeable sample showed that the flowers in the heads had developed almost to the point of pollination, but that pollen was either not formed (rare) or was not released. Pollen grains were abnormal, usually with only one or two instead of three nuclei. These observations can account for the sterility. The plants showed other symptoms when we examined them and the videos more closely. Stems were shortened, leaves showed some epinasty (rolling parallel to the leaf axis), and tillering was excessive (5-8 per plant) - much more than in earth grown plants (3-5 per plant), which accounted for the large number of heads as well as the dense vegetative canopy before head formation. 
The sterility and other plant features of the Mir-grown plants are typical of cereal plant responses to ethylene. To test the possibility that ethylene was responsible for the abnormalities of our Mir wheat, a series of experiments were carried out during the years following the space experiments (Campbell et al., 2001). Measurements of the Mir atmosphere showed 1.1 to $1.7 \mu \mathrm{mol} \cdot \mathrm{mol}^{-1}$ ethylene (moles per mole of air) prior to and during flowering of our plants. When earth-grown plants were exposed to 1 to $20 \mu \mathrm{mol} \cdot \mathrm{mol}^{-1}$ ethylene, plants exhibited all the symptoms of the Mir wheat including sterility. This included the abnormal pollen and halting of flower development just before pollen would normally be released. Thus, the case is very strong that all of the abnormalities of Mir wheat were caused by ethylene in the Mir atmosphere. The implication is that normal plants could be growth from "seed to seed" in microgravity if all other conditions were suitable as in ground experiments. So far plants have not been grown through a life cycle in an ethylene-free atmosphere in microgravity, but such experiments are planned by others. In one follow-up experiment, a cultivar of wheat (Apogee) more resistant to ethylene and also short enough to be grown in Svet was grown through two generations in Mir (Levinskikh et al., 1999). Seed yields were low, but the seeds were viable.

Although results will not be discussed here, laboratory studies of the frozen wheat were successful (summarized in Salisbury, 1997; Levinskikh et al., 2000). The cuvettes enclosing the plants were only used during the 39-d, 1996/97 experiments, but it was possible from $\mathrm{CO}_{2}$ and $\mathrm{H}_{2} \mathrm{O}$ data from the IR analyzers to calculate photosynthesis and transpiration rates (Monje et al., 2000).

There are many lessons to be learned from these experiments. One is the importance of being able to do follow-up experiments based on results from previous experiments. A single experiment in space, carried out by a given team, may well produce results that are in themselves only marginally valuable. Follow-up studies can be most helpful. We also learned that it can be easy to overlook potentially important parameters, in this case, ethylene!

\section{REFERENCES}

Campbell, W.F., F.B. Salisbury, B.G. Bugbee, S. Klassen, E. Naegle, D.T. Strickland, G. E. Bingham, M. Levinskikh, G.M. Iljina, T.D. Veselova, V.N. Sytchev, I. Podolsky, W.R. McManus, D.L. Bubenheim, J. Stieber, and G. Jahns, Comparative floral development of Mir-grown and ethylene-treated, earth-grown Super Dwarf wheat, J. Plant Physiol. 158, 1051-1060, 2001.

Campbell, W.F., D.T. Strickland, D. Bubenheim, F.B. Salisbury, P.S. Hole, L. Gillespie, M. Levinskikh, and I. Ivanova, Comparison of long-term storage in chemical fixatives on morphology and anatomy of Super-Dwarf wheat. Abstract. Presented at the 1996 COSPAR meeting in Birmingham, United Kingdom, 1996.

Dutcher, F.R., E. Hess, and T.W. Halstead, Progress in plant research in space [experiments from 1987 to 1992] Adv. Space Res. 14(8), 159-171, Pergamon/ Elsevier Science Inc. Tarrytown, NY, 1994.

Ivanova, T.N., Yu. A. Berkovich, A.L. Mashinsky, and G.I. Meleshko, The first "space" vegetables have been grown in the "Svet" greenhouse by means of controlled environmental conditions, Microgravity Q. 2(2), 109-114, 1992.

Levinskikh, M.A., V.N. Sytchev, T.A. Derendyaeva, O.B. Signalova, F.B. Salisbury, W.F. Campbell, G.E. Bingham, D.L. Bubenheim, and G. Jahns. Analysis of the spaceflight effects on growth and development of Super Dwarf wheat grown in the Svet greenhouse. J. Plant Physiol. 156, 522-529, 2000.

Levinskikh, M.A., V.N. Sytchev, I.G. Podolsky, and G.E. Bingham, Final plant experiments on Mir provide second generation wheat and seeds. Abstract. Amer. Soc. Gravitational and Space Biol. Ann. Meetings, 4-7 Nov., Seattle, WA, 1999.

Lewis, N., Plant metabolism and cell-wall formation in space (microgravity) and on earth, 1992-1993 NASA Space Biology Accomplishments, NASA Technical Memorandum, p. 241-244, 1995.

Mashinsky, A.L., I. Ivanova, T. Derendyaeva, G.S. Nechitailo, and F.B. Salisbury, From seed-to-seed experiment with wheat plants under space-flight conditions, Adv. Space Res. 14, (11)13-(11)19, Pergamon/Elsevier Science Inc., Tarrytown, NY, 1994.

Merkies, A.I. and R.S. Laurinavichyus, Complete cycle of individual development of Aribidopsis thaliana Haynh plants at Salyut orbital station, Dokl. An SSSR 271(2), 509-512, 1983.

Monje, O., G.E. Bingham, F.B. Salisbury, W.F. Campbell, J.G. Carman, B.K. Eames, V. Sytchev, M.A. Levinskikh, and I. Podolsky. Canopy photosynthesis and transpiration in microgravity: Gas exchange measurements aboard Mir. Adv. Space Res. V26(2), 303-306, 2000.

Nechitailo, G.S. and A.L. Mashinsky, Space Biology: Studies at Orbital Stations, Moscow: Mir Publishers, (ISBN 5-03-002289-9), 1993.

Salisbury, F.B., Growing Super-Dwarf Wheat in Space Station Mir. Life Support \& Biosphere Sci. 4, 155-166, 1997. 